\title{
EL TALLER DE MARQUETERIA J. SAGARRA DE BARCELONA (1833-2003) HISTORIA DE UNA SAGA DE ARTESANOS J. SAGARRA MARQUETRY WORKSHOP IN BARCELONA (1833-2003) THE HISTORY OF A FAMILY OF ARTISANS
}

Pilar Soler García*

Doctora Historia del Arte Universidad de Barcelona

\section{Resumen}

Este artículo presenta el recorrido vital y profesional de la saga barcelonesa de los Sagarra y del taller de marquetería familiar, que inició su actividad el año 1833 en el barrio del "Raval" de la ciudad. A lo largo de los 170 años de existencia, aproximadamente 130 estuvieron dedicados a la realización de marquetería artesana, hasta su cierre el año 2003. El interés por este taller familiar radica en el hecho que el largo período de existencia permite acercarse al estudio de la evolución del mismo y las relaciones que se establecen entre arte, artesanía e industria. Al mismo tiempo, la evolución de dicho taller puede servir de paradigma a otros oficios que, como éste, han ido declinando y de algunos que incluso han desaparecido. El análisis se basa en la documentación referente a esta empresa recogida en el Gremio de Tenderos Revendedores de la Ciudad de Barcelona de la Cofradía de San Miguel Arcángel y en la documentación gráfica que ha conservado el archivo de J. Sagarra ${ }^{1}$.

Palabras clave: Barcelona, marquetería. artes decorativas, oficios.

\section{Abstract}

This article presents the professional and vital journey of a Barcelona family lineage: J. Sagarra's workshop, that started its activity in 1833 and survived in the "El Raval" neighborhood over 170 years, 130 of which dedicated to craftsman's marquetry, until it's final closure in year 2003. The interest in this family workshop and its evolution and relationship with art and industry lies in de long period of dedication ti this craft and also to the fact that it's evolution may serve as paradigm to other crafts that, like marquetry, have lost presence or have even disappeared. The analysis is based on documentation on this workshop collected from de Barcelona Resellers Shopkeepers Guild, the Saint Michael Archangel's Brotherhood and de graphic documentation preserved by J. Sagarra.

Keywords: Barcelona, marquetry, decorative arts, crafts. 
El taller de la familia Sagarra ha trabajado en la realización de marquetería de gran calidad artística a lo largo, aproximadamente, de 130 años. Además de dejar huella en el oficio por su maestría en esta especialidad del arte decorativo, en la ciudad de Barcelona, en su obrador han practicado y aprendido la profesión muchos de los artífices que se han dedicado a esta actividad. La documentación gráfica que se ha localizado en la empresa es una fuente de información muy interesante para poder estudiar la evolución de los gustos en la decoración del mobiliario a lo largo de un período muy amplio, que comprende diferentes momentos históricos.

También ha sido muy útil para este trabajo la documentación generada por la Cofradía de San Miguel Arcángel del Gremio de Tenderos Revendedores de la ciudad de Barcelona, a partir de 1833, cuando Joan Sagarra Mayol entró a formar parte de dicha entidad. El gremio, creado en el año 1447, estuvo activo de manera continuada hasta que, a principios del siglo XIX, nuevas disposiciones legales llevaron a la desaparición de las organizaciones gremiales. El 13 de octubre de 1817 el Gremio de Tenderos Revendedores se constituyó en Montepío y, con la desamortización de Mendizábal en 1835, las agrupaciones de ese tipo que aún sobrevivían tuvieron que someterse a la Ley de Asociaciones del 29 de enero de 1839. Después de complicadas negociaciones se redactaron las nuevas ordenanzas, por las que se rigieron a partir del 18 de junio de $1843^{2}$, quedando constituida como Asociación de Socorros Mutuos de Tenderos Revendedores. Pasaban a ser socios de la renovada entidad todos los cofrades que estaban matriculados en el antiguo libro del citado gremio ${ }^{3}$.

La asociación, que sigue estando ubicada todavía en la plaza del Pino n. 3 de Barcelona, conserva un libro registro donde están anotados todos los asociados, así como las altas y bajas producidas a lo largo de los años ${ }^{4}$, desde sus inicios. El expediente Sagarra aporta datos relativos a la familia, que al mismo tiempo permiten percibir la evolución de algunos aspectos generales de la sociedad. Sirva de ejemplo: con cada generación aumenta la longevidad, la mortalidad infantil es menor, algunos oficios se transforman absorbidos por la industria y otros, simplemente, dejan de existir.

Las primeras noticias de este taller artesano son, a veces, inconexas pero siguiendo la secuencia documental hasta donde ha sido posible, hemos podido situar las diferentes ubicaciones que ha ido ocupando en la ciudad a lo largo de cinco generaciones de artesanos y su evolución en el campo laboral. Cuando Joan Sagarra Mayol entró a formar parte del gremio (1833) se inscribió con el oficio de sombrerero y el taller estaba situado en la calle del Carmen $\mathrm{n}^{\circ} 3$, pero dos años más tarde (1835) se encontraba en la Rambla $n^{0} 75$ y en la calle Cadena $n^{0} 22^{5}$.

Los cambios en la situación de los gremios, a los que se ha aludido anteriormente, tuvieron como consecuencia una paralización en los trámites burocráticos que provocaron que, después de la muerte de Joan Sagarra Mayol (1797-1842) no se anotara el alta de su heredero Josep Sagarra Selvasembrada (1827-1884) en el registro del gremio hasta el 5 de enero de 1864, donde se inscribió como ebanista. El taller se encontraba entonces en la calle de la Paja ${ }^{\circ}$ 35 (actualmente $\mathrm{n}^{\circ} 37$ ). 
El tercer personaje de la saga, Joan Sagarra Viola (1856-1920), fue quien introdujo en el taller familiar el oficio de la marquetería, que aprendió en Aix-enProvence (Francia) alrededor de $1875^{6}$, dedicándose a partir de entonces a todas las especialidades derivadas del oficio de marquetero, o sea, a la marquetería artística y cualquier otro trabajo en maderas, metales y otros materiales diversos, susceptibles de ser laminados para poder ser manufacturados en la sierra de ballesta. Al producirse esta especialización el taller continuaba en la calle de la Paja $n^{\circ} 35$, donde trabajaba todo el grupo familiar, además de servir de vivienda.

Joan Sagarra Viola contrajo matrimonio con Concepción Miró, de cuyo enlace nacieron seis hijos, cuatro de ellos varones, que aprendieron el oficio paterno trabajando en el taller familiar. Durante el período modernista la empresa era conocida bajo el nombre de "J. Sagarra e hijos".

\section{El período modernista (1890-1910)}

Durante el siglo XIX Barcelona inició un proceso cada vez más acelerado de industrialización. Este fenómeno tuvo como consecuencia el crecimiento demográfico de la ciudad, así como la consolidación de un grupo dirigente, la burguesía. Esta clase social tenía magníficas posibilidades de consumo, que aumentaron con los negocios de exportación de vino debido a la filoxera en Francia y con la llegada de capitales de Cuba y Filipinas. Fueron llegando a Barcelona profesionales de varios oficios y aprendices procedentes del campo, buscando una mejora en su situación económica. Estas circunstancias produjeron un crecimiento en la construcción de viviendas con una distinción muy clara entre la sencilla vivienda del obrero y la vivienda de las clases dominantes, que evolucionó hacia los movimientos estéticos europeos, pasando primero por los gustos historicistas, para llegar al Art Nouveau que triunfaba en Europa.

El aumento de la construcción, con la correspondiente necesidad de productos de madera, ya fuera para obra o para la decoración de interiores, fue el origen de numerosos talleres dedicados a la carpintería y a la ebanistería, ubicados muchos de ellos en "Ciutat Vella" y el "Raval", donde la producción de mobiliario ocupaba gran parte de los talleres de la zona. Cabe decir que en la calle de la Paja, donde trabajaba y vivía la familia Sagarra, a mediados del siglo XIX había hasta doce carpinteros además de un almacén de madera ${ }^{7}$.

La decisión de Joan Sagarra Selvasembrada de mandar a su primogénito, Josep Sagarra Viola, a aprender el oficio de la marquetería a Francia, al parecer fue debida a la necesidad de ampliar el negocio, dándole un giro importante al introducir en el taller las artes decorativas, ya que el mismo Josep Sagarra Viola también era conocido en 1887 como tallista ${ }^{8}$. Eran los años previos al Modernismo, movimiento que daría una gran importancia a los oficios artísticos. Es decir, los Sagarra tuvieron visión de futuro además de habilidad técnica y artística.

Con la Exposición de Barcelona de 1888 el Modernismo llegó a su plenitud. A la exhibición concurrieron varios profesionales de la marquetería, entre ellos 
Josep Sagarra que junto a los hermanos Galán eran considerados los más notables profesionales del momento ${ }^{9}$. El movimiento modernista tuvo una incidencia importante en Cataluña, principalmente en la arquitectura y en las artes decorativas, muchas de las cuales como la escultura, la cerámica o los vitrales formaban parte integral de la ornamentación arquitectónica. Asimismo en los interiores se trabajaba con mosaicos, tejidos, cortinajes, tapizados y mobiliario con marqueterías abundantes, así como también el pirograbado, los esmaltes, la metalistería o la talla, ya que la casa modernista era concebida por sus mejores arquitectos como una unidad armónica.

Pese a que la duración del movimiento modernista fue relativamente corta, ya que su desarrollo pleno se sitúa aproximadamente entre 1890 y 1910, dejó numerosas muestras no tan sólo en Barcelona sino en otras ciudades catalanas y españolas. Puede decirse que muchos de los decoradores y ebanistas del momento (Gaspar Homar, Casa Busquets ${ }^{10}$, Vda. Ribas o Esteva y Hoyos, entre los más importantes) usaron de la marquetería para embellecer sus creaciones.

La familia Sagarra, que introdujo la marquetería en su empresa en el período inicial del modernismo, adquirió notoriedad profesional por haber realizado marqueterías para Gaspar Homar, artista decorador que colaboró durante el período modernista con los arquitectos de más prestigio, especialmente con Domènech y Montaner. Algunas de estas marqueterías formaban parte del mobiliario de la casa Lleó Morera, del paseo de Gracia $\mathrm{n}^{0} 34$, que en casi su totalidad fue adquirido por el Museo de Arte Moderno, y se expone en la actualidad en el Museo Nacional de Arte de Cataluña (MNAC) ${ }^{11}$. En dicho mobiliario se pueden apreciar los proyectos para marquetería de Josep Pey y la gran perfección en su ejecución por Joan Sagarra e hijos, así como la talla de Joan Carreras y la extraordinaria calidad de los materiales utilizados.

El mobiliario modernista tenía como característica importante que estaba realizado en maderas claras, en las cuales destacaba la introducción del color, principalmente de la marquetería. Eran muchas las maderas utilizadas, pero las principales eran: el palo rosa, la jacaranda, el plátano, el fresno, la bubinga, el sicomoro, la caoba, el cerezo, el emboé, el limoncillo, la majagua, el roble, el nogal o el doradillo. A las chapas de madera se añadían metales laminados como el latón, el estaño, el cobre o el zinc, además de materiales como el nácar, el hueso o el marfil. Eran materiales a veces difíciles de obtener y bastante costosos, pero Sagarra siempre tuvo el almacén bien surtido de ellos.

Durante este período la ubicación de la empresa seguía en la calle de la Paja $n^{\circ}$ 35, hasta que el año 1908 la encontramos en el $n^{\circ}$ 3-5 de la misma calle, en un local mucho más pequeño, quedando a partir de entonces separado el lugar de trabajo de la vivienda privada ${ }^{12}$.

\section{El período de entreguerras (1914-1936)}

Esta etapa de la historia, pese a verse alterada por situaciones como la Dictadura de Primo de Rivera y la Segunda República, que acabaron desembocando en la Guerra Civil, fue de una gran vitalidad y de cambios 
importantes en muchos ámbitos en Barcelona. Al principio de los años veinte, la situación política y social llegó a ser muy complicada, con la guerra de África como trasfondo. La violencia en las calles de la ciudad era incontrolable, hasta el punto que muchos empresarios cerraron sus negocios. Uno de estos empresarios fue Gaspar Homar, quien habiendo recibido amenazas decidió cerrar sus talleres, dedicándose a la venta de antigüedades y artículos decorativos en su tienda de la calle Canuda $\mathrm{n}^{\circ} 4$, actividades que ya venía realizando anteriormente.

Las tendencias decorativas en el mobiliario en las que se trabajaba durante los años de entreguerras eran diversas: el Novecentismo clasicista, que había prefigurado como proyecto el Modernismo ${ }^{13}$, compartía espacio con muebles de inspiración Déco. Asimismo una tímida llegada del Racionalismo y el diseño, aportaban simplificación en las formas debido al concepto de utilidad y a la aceptación de la máquina como auxiliar del trabajo del hombre, buscando la belleza más en la utilidad que en la ornamentación.

Diferentes circunstancias contribuyeron a que a principios de la década de 1920 el negocio de la familia Sagarra se ramificase en tres talleres independientes, si bien todos tenían como base el oficio de la marquetería. El detonante de los cambios fue el fallecimiento de Joan Sagarra Viola que tuvo lugar en 1920, pero seguramente diversos acontecimientos provocaron esta dispersión. Según Manuel García Martín ${ }^{14}$, el cierre de los talleres Homar fue la causa indirecta de que el negocio familiar se fragmentase, porqué este famoso decorador ayudó a algunos de los empleados en sus talleres a establecerse por su cuenta, entre los que se contaban dos de los hermanos Sagarra: Josep y Enric. El primero se estableció en la calle Ferlandina $\mathrm{n}^{0} 3$, dedicándose preferentemente a la confección de marquetería artística a la manera tradicional, mientras que el segundo creó una empresa dedicada a la fabricación industrial de paneles decorativos para mobiliario, que se ubicó en la calle Hospital, 89-91. De los dos hermanos menores, Joan al parecer murió joven y tras la defunción del padre la titularidad del taller pasó a su hijo menor, Jaume.

Las nuevas empresas de la familia Sagarra se fueron consolidando, siendo unos especialistas muy bien considerados, principalmente el taller de la calle Ferlandina que Josep Sagarra Miró (1886-1959) regentaba. Éste, casado y padre de tres hijos, como primogénito pasó a formar parte de la Asociación de Socorros Mutuos el año 1922. La formación de los hijos fue desde su infancia dirigida al aprendizaje del oficio paterno iniciándose entre juegos para pasar sin apenas sentirlo a trabajar en el taller. Josep (1915-2010), el primogénito, fue el único que recibió formación escolar mientras Fernando (1918-2011) y Joan (1921-2001) recibían alguna instrucción del párroco de la iglesia de Belén de la cual era acólitos. Fernando, destinado a ser el encargado del taller, empezó a trabajar formalmente a los diez años junto a su tío en el taller de la calle de la Paja y a los doce años pasó a trabajar con su tío Enric en la fábrica de paneles industriales, mientras ayudaba a su padre aprendiendo a realizar la marquetería de la manera más tradicional. A los catorce años empezó a trabajar como especialista en marquetería en la importante empresa de ebanistería Mainou, hasta que en 1936, cuando su hermano mayor fue llamado a filas, regresó al taller paterno ${ }^{15}$. 
Durante este período la industrialización de la ebanistería se generalizó e hizo que el mobiliario fuera más asequible para la clase obrera. Por primera vez éste sector de la sociedad tenía la posibilidad de acceder a un mobiliario para el hogar que no atendía tan sólo a las necesidades más básicas, sino que se les ofrecía un producto pensado y fabricado con la intención de satisfacer el gusto de este grupo social, cada vez más numeroso.

Estas circunstancias llevaron a la necesidad de realizar marqueterías seriadas, más económicas, para ser incorporadas a muebles modestos. A partir aproximadamente de $1915^{16}$, los talleres de la familia Sagarra se dedicaron a su manufactura, principalmente por encargo de la empresa de Santiago Bolibar. Esta empresa las comercializaba a gran escala sirviéndose de muestrarios, en los que ofrecía también la metalistería que fabricaba en su taller de la plaza Letamendi ${ }^{17}$. Ello les proporcionaba encargos en todo el país e incluso exportaban al extranjero. Debido a la fuerte demanda de esta marquetería los talleres de la familia Sagarra tuvieron hasta los años treinta trabajo seguro para varios obreros. La utilización de: motivos florales, jarrones, cestos, orlas, cintas... en la marquetería seriada podría justificarse en el gusto de una clientela que no buscaba la modernidad, sino la adaptación en el propio ámbito de aquello que siempre se había considerado "elegante".

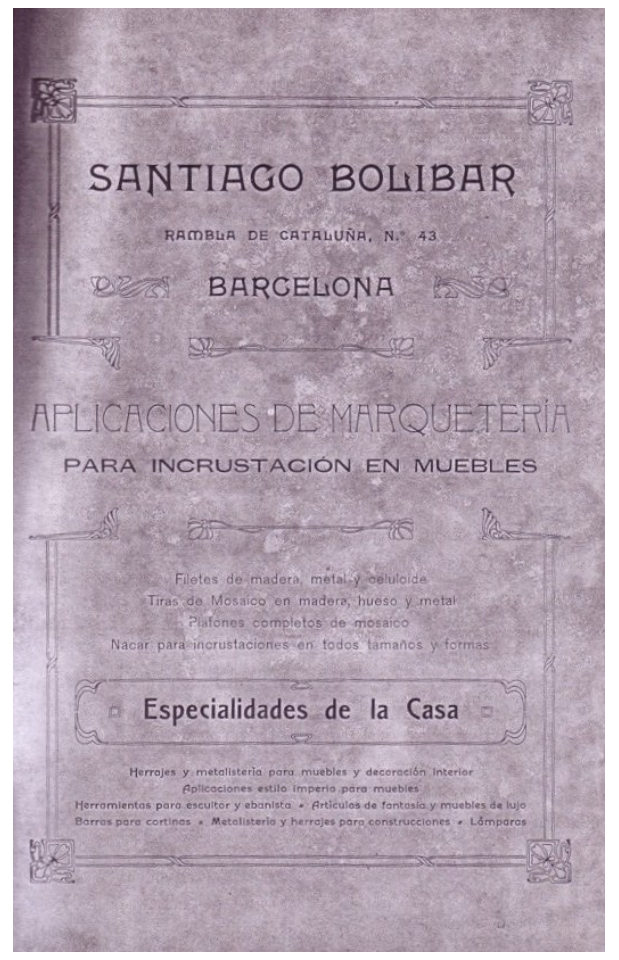

Fig. 1. Muestrario archivo J. Sagarra. Barcelona. c.1918. Foto autora.

El interés de las empresas dedicadas a la fabricación de esta tipología de mobiliario se puso de manifiesto en el concurso que se llevó a cabo, de manera previa a la Exposición Internacional del mueble que tuvo lugar en Barcelona, entre el 13 de septiembre y el 2 de diciembre de 1923. El concurso fue organizado 
por el Fomento de las Artes Decorativas (FAD) que editó un libro, Per la bellesa de la llar humil18, en el cual aparecían los muebles que se habían presentado al certamen, destacando los que habían sido premiados. En la publicación se pone de manifiesto la importancia del propósito. La participación fue general por parte de industriales y ebanistas, muchos de ellos clientes del taller de J. Sagarra y también ofrecía sus productos (metalistería y marquetería) la empresa de Santiago Bolíbar.

En este mobiliario que se mueve entre el Novecentismo y el Déco es notable el gusto por modelos anteriores, aunque transformados y adaptados a las dimensiones pertinentes de los pequeños pisos de las zonas urbanas: algunas de las cintas o las orlas florales de las marqueterías recuerdan el período del Romanticismo, mientras también encontramos algunas marqueterías de inspiración Déco. Eran modelos destinados a una capa muy amplia de la sociedad al ser realizados industrialmente.

Contrastando con el mobiliario anteriormente descrito algunos decoradores, entre ellos Santiago Marco, entonces Presidente del Fomento de las Artes Decorativas (FAD), mostraban su interés por el mueble déco francés, lo que les llevó a participar en la gran Exposición Internacional de Artes Decorativas, que tuvo lugar en París el año 1925. Se trataba de muebles de lujo en los cuales las marqueterías acostumbraban a ser de maderas tropicales, metales, madreperla, carey y marfil. Esta tendencia de la moda no llegó a adquirir carta de naturaleza, como en Francia, pero sí que tuvo algunos practicantes, entre los cuales destacaban Santiago Marco y Evarist Mora. En la Exposición Internacional de Barcelona del año 1929, el FAD liderado por Santiago Marco presentó el Pabellón de Artistas Reunidos, en el cual participaron gran parte de los socios de la entidad. El estilo era Déco tanto en la arquitectura como en el interior.

mamequeterian artistica

tableros fantasía

enripue

saigarira

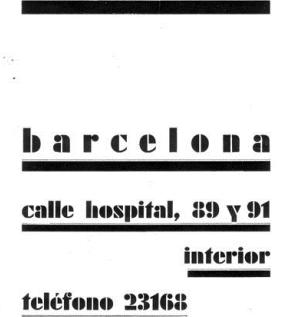

Fig. 2. Muestrario archivo J. Sagarra. Barcelona. Impreso Gráficas Rodés, S.A. 1929. (Colección autora) 
Evidentemente, el taller J. Sagarra seguía trabajando con los mejores decoradores en artículos de calidad, para Santiago Marco en el mobiliario que éste presentó en París o para Evarist Mora en las marqueterías presentadas en el I Salón de Artistas Decoradores que tuvo lugar en Barcelona en 1936. No obstante, es interesante la faceta de la marquetería elaborada en serie porque fue lo más cerca que esta empresa estuvo de la marquetería industrial.

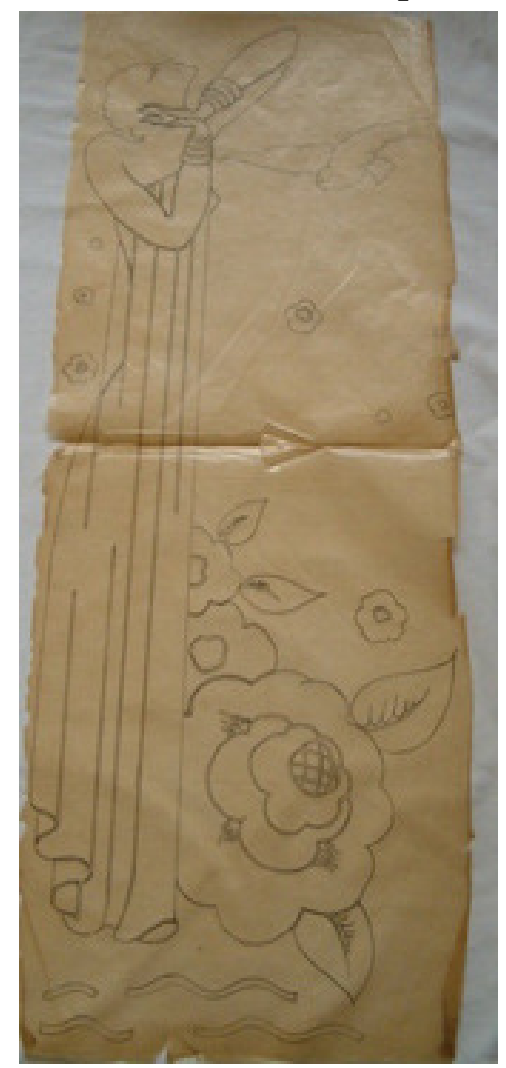

Fig. 3. Jener, Eduard. Dibujo para marquetería $(0,90 x 0,40 \mathrm{~cm}$.), para la empresa de cosméticos Myrurgia. Barcelona, 1930. Archivo J. Sagarra (Colección autora)

\section{De la postguerra al "desarrollismo" (1945-1965)}

Josep Sagarra Miró siguió al frente del taller durante toda la Guerra Civil, mientras sus tres hijos eran movilizados; su hermano Enric murió en 1938 y el taller de la calle de la Paja siguió funcionando con Jaume al frente.

Aunque la guerra finalizó en 1939, la situación no se normalizó hasta el término de la Segunda Guerra Mundial en Europa. Josep Sagarra Miró siguió trabajando hasta que la salud se lo permitió, pero cuando sus hijos fueron licenciados del ejército dejó en sus manos la deriva del negocio. Con el cambio generacional se produjo una concepción más moderna de la empresa: el hijo mayor tomó a su cargo la dirección administrativa y el mediano pasaría partir de finales de los años cuarenta a dirigir el taller, asistido por su hermano menor, cuatro oficiales y aprendices. Es decir, ya no era el artesano quien dirigía la empresa desde el taller, sino que contaba con una persona dedicada a la organización del mismo. 
A pesar de las dificultades de todo tipo que atravesaba el país, pronto empezaron a tener encargos lo que se manifestaba en el hecho de que se reincorporaron a la empresa, recién terminada la guerra, algunos de los operarios que trabajaron en el taller anteriormente y hacían tantas horas extraordinarias como podían. A ello contribuyó, sin duda, que el taller no había sido desmantelado durante la contienda y por ello contaba con el utillaje intacto y también con un almacén bien surtido de chapas y otros materiales que les permitieron aceptar encargos de manera inmediata ${ }^{19}$. Estos encargos procedían muchas veces de restauraciones, pero la demanda de obra nueva también era muy importante.

A partir de mediados de los cincuenta, los encargos se acumulaban y los hermanos Sagarra decidieron habilitar el almacén de la calle San Vicente $n^{\circ} 27$ para trabajar en él, creando así un anexo al taller de la calle Ferlandina. Fernando seguía dirigiendo el taller principal y Joan tomó a su cargo el anexo, teniendo que aumentar la plantilla a seis oficiales y cuatro aprendices. Lo anteriormente expuesto demuestra la importancia de este taller de marquetería, puesto que no se conoce ningún otro de la época que tuviera tantos asalariados fijos sin contar algunos que acudían a trabajar por horas ${ }^{20}$.

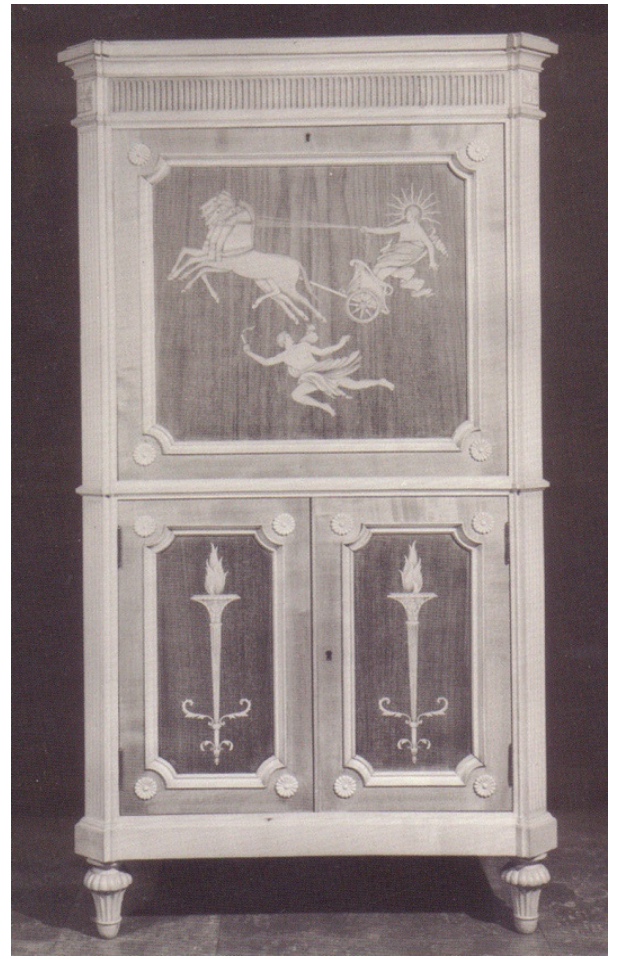

Fig. 4. BLANXART, Eduard. Mueble para colección de encendedores. Barcelona 1952. Archivo Blanxart. Marqueteria J. Sagarra. (Colección autora)

J. Sagarra recibía los encargos más interesantes de los decoradores de más prestigio, entre ellos Jaume Llongueres, Santiago Marco, Josep Mir o Evarist Mora, que ya eran clientes antes de la Guerra Civil, a los que se añadieron después de ésta Enric Cluselles, Llucià Navarro o Antonio Calonje; todos ellos 
dedicados a las artes plásticas que ejecutaban los proyectos para marquetería más o menos asiduamente. Entre los años 1940 y 1970 el taller contaba también con Ramón Marsiñac, un dibujante externo que les preparaba los proyectos cuando no provenían de artistas decoradores. A causa de destrozos ocasionados durante la contienda, muchos de los proyectos que preparaban los decoradores eran solicitados por las instituciones de la ciudad y en número importante para arte sacro, entre los que cabe destacar las marqueterías proyectadas por Evarist Mora para la basílica de Nuestra Señora de la Merced de Barcelona o las que Llucià Navarro proyectó para la parroquia de San Antonio Abad de Vilanova y la Geltrú que realizó el taller J. Sagarra con muy bellos materiales y una magnífica ejecución ${ }^{21}$.

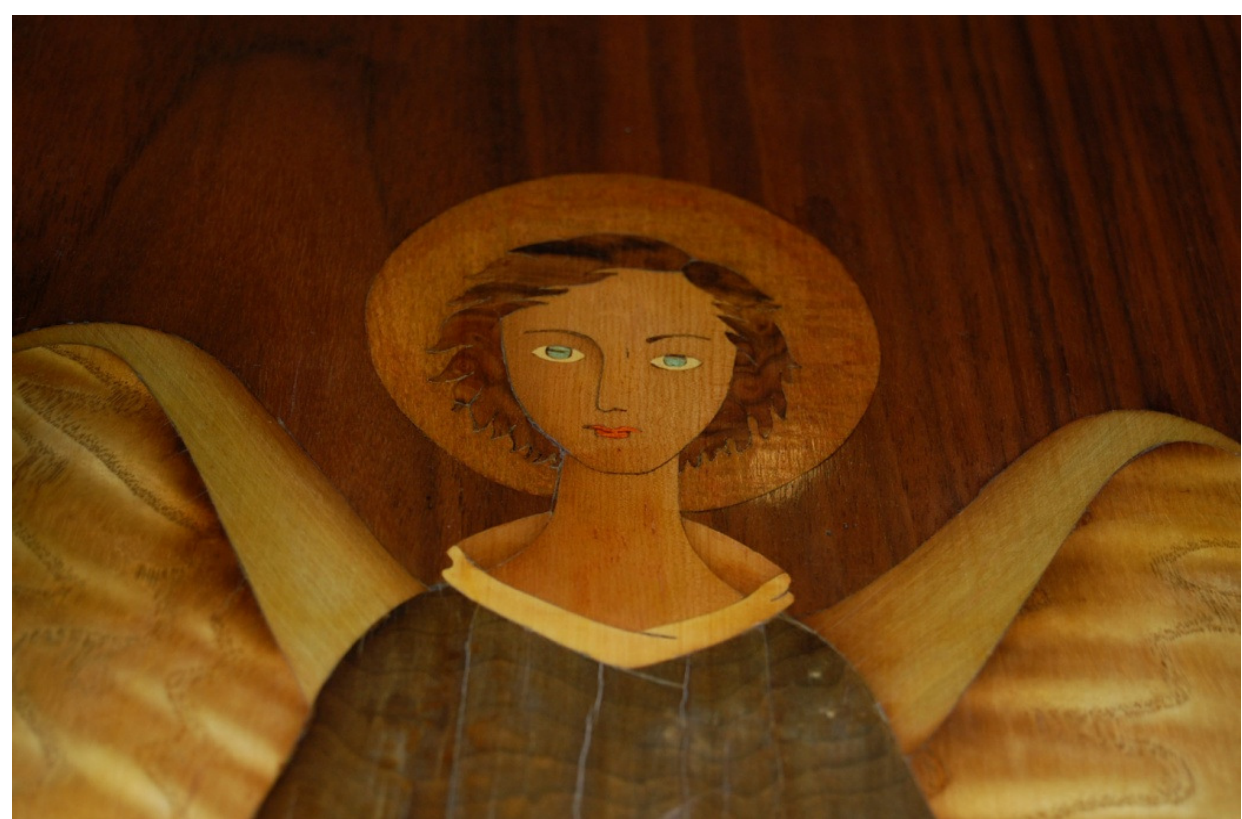

Fig. 5. MORA, Evarist. Detalle marquetería basílica de Nuestra Señora de la Merced (0,20x0,32 cm.). Barcelona 1955. Marquetería J. Sagarra. Materiales: caoba, fresno ondulado, majagua, coral, sicomoro, peral, etc. (Colección autora)

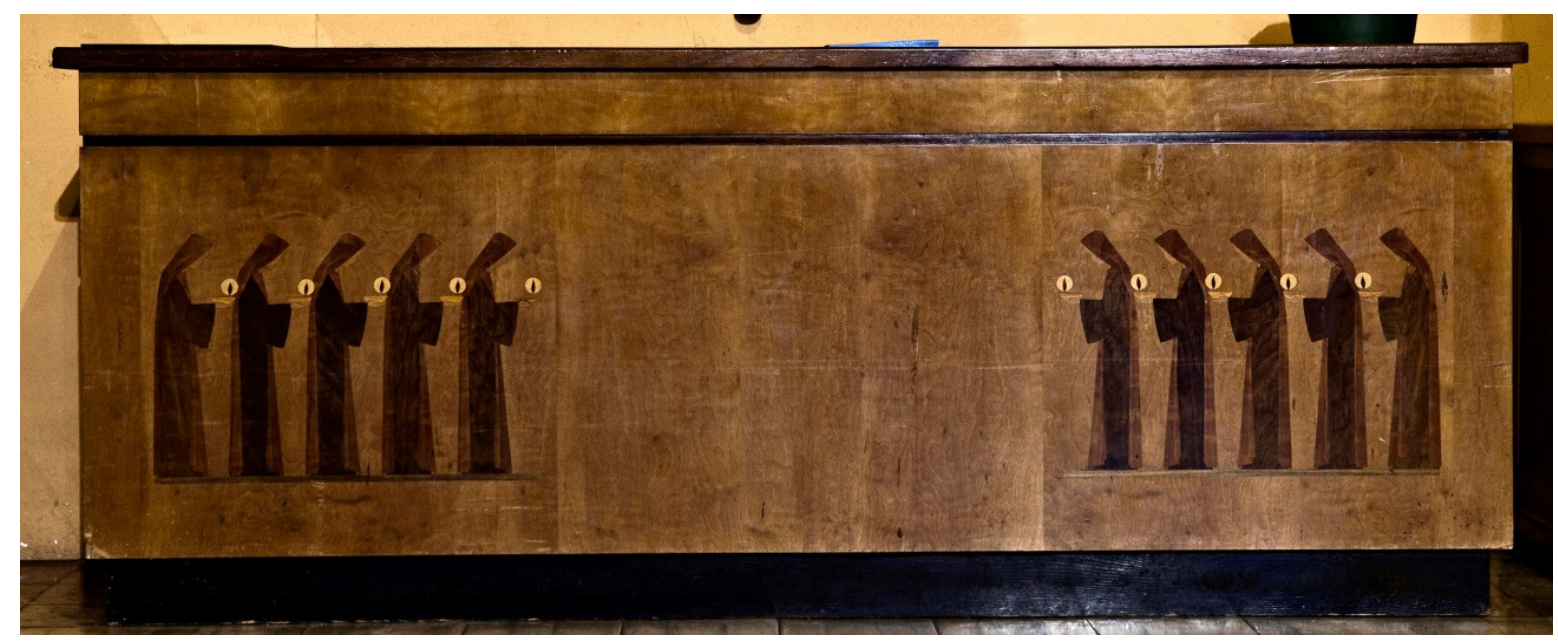

Fig. 6. NAVARRO, Llucià. Detalle marquetería altar lateral de la parroquia de San Antonio Abad (1,86x0,40cm.) Vilanova i la Geltrú 1959-60. Marquetería J. Sagarra (Colección autora) 
Naturalmente había encargos de particulares de gran interés, como un piano con marqueterías proyectadas por Enric Clusellas ${ }^{22}$, que fue presentado en la Exposición Nacional de Artes Decorativas que tuvo lugar en Madrid en la primavera de 1947, o las que diseñó Evarist Mora para el Salón Rosa o los establecimientos comerciales del Dique Flotante, también en los años quarenta. Pero en este período no se volvió a la producción masiva de marquetería seriada para la empresa de Santiago Bolibar, ya que ante una situación inestable, el taller de J. Sagarra, optó por una diversificación mayor de la clientela. Esto no quiere decir que no ofrecieran a sus clientes una versión modernizada de la marquetería seriada, pero ésta vez iba dirigida a tiendas y talleres ebanistas directamente. Muestra de ello son la multitud de perchas y consolas con marqueterías que hoy podemos encontrar en todos los almacenes de "brocanters", así como en todos los talleres de restauración, en diferentes medidas y calidades, pero todas con un cierto espíritu neoisabelino.

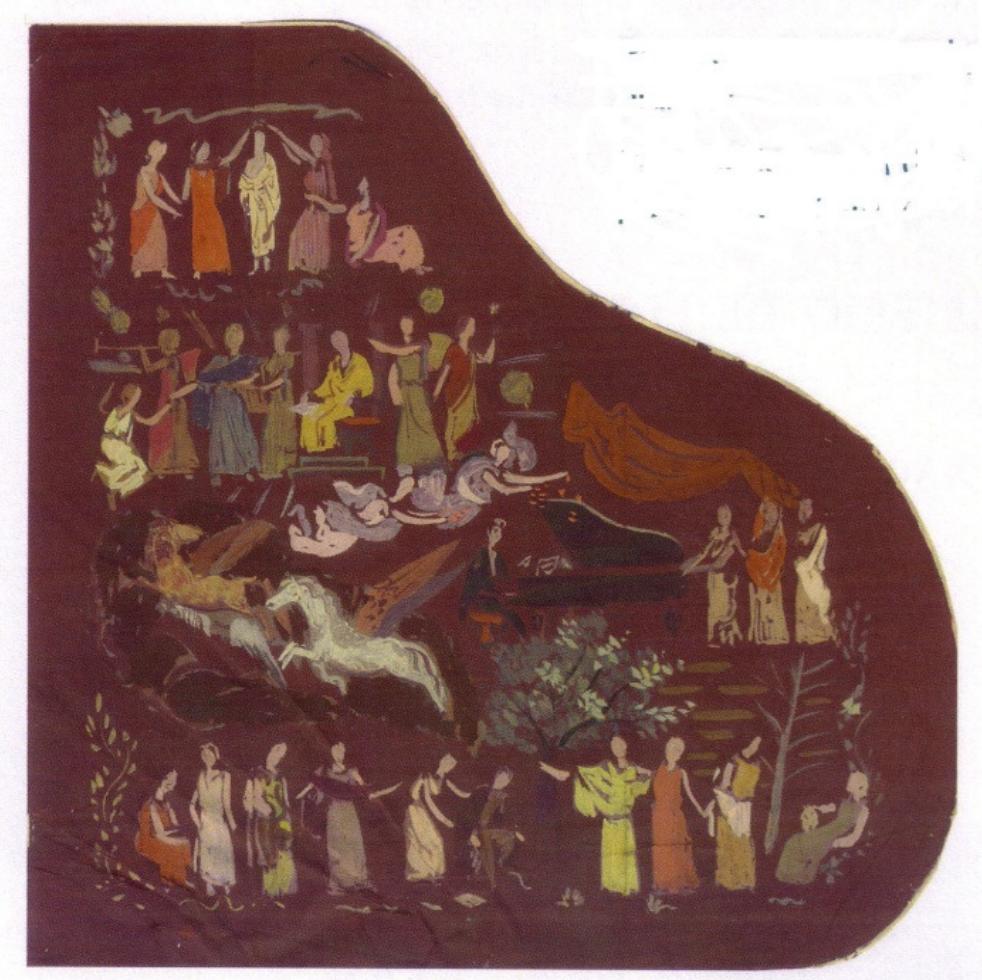

Fig. n. 7. Clusellas, Enric. Maqueta marquetería del piano presentado en Madrid en la Exposición Nacional de Artes Decorativas. 1947. Archivo Clusellas. Mueble de Llorenç Casas. Marquetería J. Sagarra (Colección autora)

En la práctica, como cualquier atisbo de vanguardia en la decoración parecía fuera de lugar durante los años que siguieron a la Guerra Civil, se volvió a los modelos del pasado, en la mayoría de los casos creando una serie de neo estilos enraizados en el mobiliario del siglo XIX. A pesar de ello, actualmente se están descubriendo muchos más muebles Déco de los que parecía haber ${ }^{23}$. A finales de los años cincuenta, la demanda de marquetería era muy grande, 
principalmente para una nueva burguesía nacida como consecuencia de la postguerra y también para la ornamentación de las iglesias.

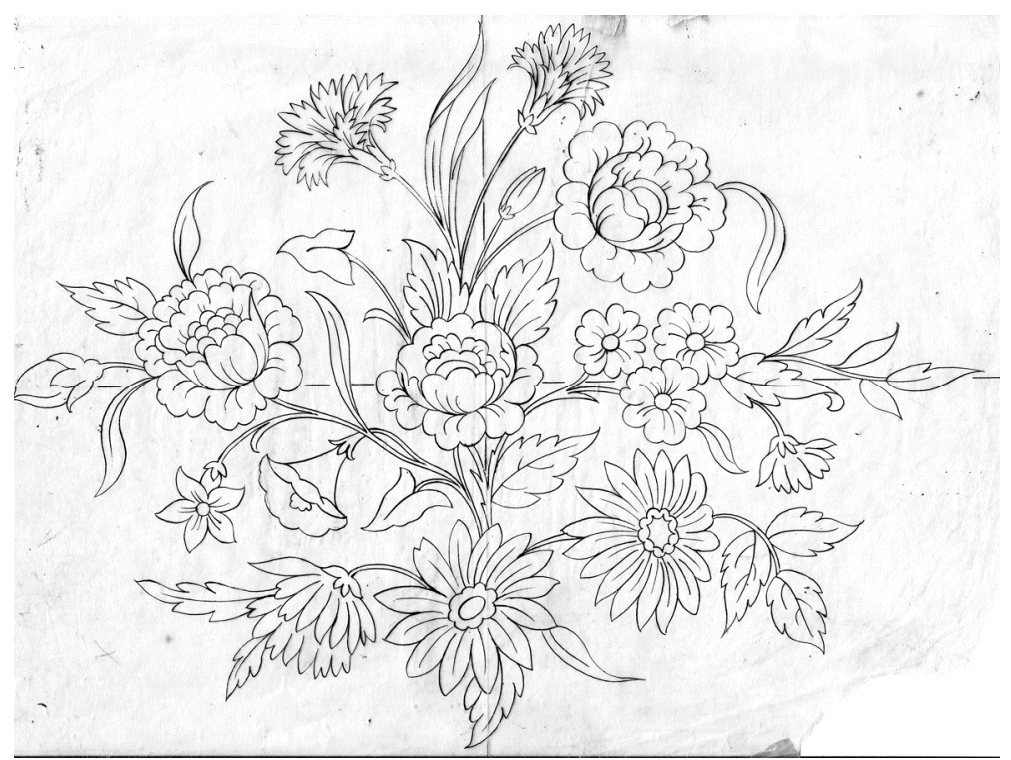

Fig. 8. Calonge, Antoni. Dibujo para marquetería (0,265x0,26 cm.) Barcelona c.1960. Archivo J. Sagarra. (Colección autora)

\section{Del éxito a la decadencia del oficio (1966-2003)}

El momento culminante de trabajo de esta artesanía, fue a lo largo de los años sesenta, luego poco a poco fue cediendo la demanda, si bien hasta principios de los ochenta no fue muy perceptible, porque el aumento de la población y una mejora considerable del poder adquisitivo de una incipiente clase media compensaban la caída de los encargos de la clientela habitual.

La disminución se produjo de manera paulatina. Se dejó de usar como obrador el almacén de la calle San Vicente. Tampoco se dieron circunstancias traumáticas, dado que los operarios, contratados algunos de ellos en los años de la postguerra fueron llegando a la edad de jubilación y al no tener relevo generacional los hermanos Sagarra dejaron de preparar aprendices. En consecuencia, cuando el año 1989 el Consistorio de la ciudad expropió una parte de la calle Ferlandina para ampliar la plaza frente al Museo de Arte Contemporáneo (MACBA), el taller volvió a trasladarse al almacén de la calle San Vicente $\mathrm{n}^{\circ}$ 27, con tan sólo dos empleados en la categoría de oficiales. También fue éste el momento que eligió Josep Sagarra para jubilarse, quedando el taller en manos de Fernando y Joan.

Aunque la marquetería pasaba por un momento de poco aprecio, el taller siguió trabajando porque otras empresas fueron cerrando sus puertas como la de J. Garganter o R. Domènech llegando a la situación de que tan sólo quedaron en la ciudad J. Ordóñez ${ }^{24}$ y J. Sagarra. Este hecho propició que durante este período el trabajo de restauración para particulares, museos y anticuarios fuera en 
aumento y permitió mantener un ritmo normal de trabajo que siguió intercalándose con encargos de prestigio, como el realizado para la cripta del templo expiatorio del Sagrado Corazón del Tibidabo de Barcelona en los años 90 o los paneles decorativos para el convento de las Hijas de María en la población de Cervera (Lérida) en el año 2000, entre otros ${ }^{25}$.

Mientras tanto, el taller de Jaume se había ido especializando en la confección de rótulos comerciales, que con el fuerte crecimiento de la ciudad tenían mucha demanda. El taller de la calle de la Paja quedó pequeño y en los años cincuenta se trasladó a la calle Parlamento a un espacio mayor, donde en la actualidad el nieto de Jaume sigue fabricando rótulos comerciales con los sistemas industriales más modernos.

En el año 2001 murió Joan Sagarra, quedando Fernando Sagarra sólo en el taller con un operario. Un año más tarde se produjo la jubilación de éste por enfermedad y Fernando Sagarra, a los 85 años, decidió cerrar el negocio en Diciembre de 2003.

\section{Como conclusión}

Este estudio sobre el taller J. Sagarra, junto al de la obra de sus colaboradores artistas e industriales ha permitido comprobar que la producción de dicha empresa formaba parte de un movimiento evolutivo general en el que otras artesanías y oficios se movían en parámetros parecidos, debido al desarrollo de la industria en todos los campos ${ }^{26}$. Es importante constatar que a partir de la Guerra Civil, la marquetería continuó siendo un elemento importante en la decoración de interiores hasta que en la década de los setenta se inició el declive que llevó a la situación actual, en que la práctica de este oficio artesano puede decirse que es residual.

El proceso comercial, como el de cualquier otro producto, depende de la valoración que la hipotética clientela haga de las artes decorativas y de la demanda que ésta pueda tener en el mercado. Como explica el profesor JesúsÁngel Prieto ${ }^{27}$, lo que hay que considerar es que tan sólo han sobrevivido aquellas artesanías que han sabido dar el paso de oficio a práctica artística o aquellas que se han transformado en industrias; ni una cosa ni la otra se han dado en relación a la marquetería.

La conexión entre el arte, la artesanía y la industria es imprescindible en este arte decorativo, ya que forzosamente han de compartir los criterios de forma y color para convertir la obra creativa en materia y su aplicación a un mural o a un mueble hace necesario que el industrial ebanista participe de las técnicas y criterios de funcionamiento. En general el trabajo del artesano no recibe la consideración que merece e incluso puede pasar desapercibido.

El mobiliario es un testimonio de la vida del hombre, sus gustos, sus posibilidades económicas, las modas de su entorno social... Por eso, la marquetería como elemento decorativo en los interiores, ya sea de particulares, de la iglesia o de las administraciones públicas, es también una muestra de cada período histórico. 
A partir de los años ochenta del pasado siglo, las clases adineradas en Catalunya adoptaron el gusto por una decoración de tendencia minimalista, excluyente del color y a veces de la madera, al usar otros materiales. Esta evolución ha tenido como consecuencia la pérdida de interés de la clientela por la marquetería. A pesar de todo, no se puede olvidar que este oficio artesano tiene una larga trayectoria y que ha sobrevivido a otros momentos de abandono, pero su práctica en la actualidad ocupa a muy pocos artesanos, que la practican para una clientela muy reducida y que en general es un complemento a otras labores como pueden ser la restauración o la fabricación de marcos.

Aceptando la falta de demanda como principal motivo de la desaparición de ésta y otras artesanías, hay otros motivos sociológicos, como la no transmisión del oficio de padres a hijos y una concepción del mundo laboral en el cual el oficio manual y de producción perdió valor frente al trabajo intelectual y de servicios, lo que llevó a la falta de relevo generacional que probablemente hubiera potenciado la pervivencia y la adaptación del negocio a las nuevas necesidades de una sociedad cambiante.

\section{NOTAS}

\footnotetext{
${ }^{1}$ SOLER GARCÍA, Pilar, La marquetería artística. El taller J. Sagarra. Barcelona (1940-1965), Tesis doctoral, Universidad de Barcelona, enero 2013, pp. 39-81.

${ }^{2}$ AHCB (Archivo Histórico Ciudad de Barcelona). Sección Gremios, Serie 45-69.

${ }^{3}$ AHCB. Libro de matrículas, Juan Sagarra Mayol estaba matriculado desde el año 1833 en la página 127 del libro.

${ }^{4}$ El libro registro del Gremio de Tenderos Revendedores de la Ciudad de Barcelona en la página 892 contiene el expediente de la familia Sagarra a partir de los documentos de Fe de Vida y Óbito a lo largo de toda la genealogía.
}

${ }^{5}$ AHCB. Sección Gremios, 45-57.

${ }^{6}$ Testimonio oral de los hermanos Sagarra registrado en el taller de la calle San Vicente, 21 y 27 de enero, 2001.

${ }^{7}$ MAINAR, Josep, El moble català, Barcelona, Destino, 1976, p. 220.

${ }^{8}$ RAFOLS, J.F. Diccionario Biográfico de Artistas de Cataluña, Barcelona, Millá, 1953, p. 40.

${ }^{9}$ MAINAR, Josep. El moble català, cit., p. 28 (Según testimonio oral de Fernando Sagarra los hermanos Galán habían aprendido el oficio en el taller de su abuelo)

10 SALA, Teresa-M, La Casa Busquets. Una història del moble i la decoració del modernisme al déco a Barcelona, Barcelona, Universitat Autònoma de Barcelona, Servei de Publicacions, Publicacions i Edicions de la Universitat de Barcelona, 2006.

${ }^{11}$ FONDEVILA, Mariàngels, Gaspar Homar, Barcelona, Museu Nacional d'Art de Catalunya y Fundació "La Caixa”, 1998, pp. 187, 188, 189 y 195. En el Museo Nacional d'Art de Catalunya se encuentra, además de mobiliario, una exposición importante de artes decorativas modernistas.

${ }^{12}$ Con fecha 1 de enero de 1908 Juan Sagarra Viola contrata en arrendamiento la tienda sita en la calle de la Paja n. 3 y 5, por trescientas pesetas al año a pagar por trimestres adelantados, al propietario, marqués de Puertolás.

13 PERAN, Martí, SUÀREZ, Alicia, Y VIDAL, Mercé, "La prefiguració d'un projecte. Modernisme i Noucentisme" a El Noucentisme un projecte de modernitat, Barcelona. Ed. CCCB, 1991, p. 45.

${ }^{14}$ GARCIA MARTÍN, Manuel, La casa Lleó Morera, Barcelona, Catalana de Gas, 1988.

${ }^{15}$ Testimonio oral de los hermanos Sagarra registrado en el taller de la calle San Vicente, 27, 24- 11-2000.

${ }^{16}$ Testimonio oral de Fernando Sagarra corroborado por Santiago Bolibar, registrado en el taller de la calle San Vicente 15-12-2002.

${ }^{17}$ Santiago Bolibar. Aplicaciones de marquetería para incrustación en muebles, Barcelona, c. 1915, 1918 y 
1922.

${ }^{18}$ MARCO URRUTIA, Santiago, Per la bellesa de la llar húmil, Barcelona, Foment de les Arts Decoratives (FAD), 1926.

${ }^{19}$ Uno de los principales problemas era la dificultad para abastecerse de materiales debido a la situación de autarquía en el que se vio inmerso el país.

${ }^{20}$ Testimonio oral de los hermanos Sagarra, debidamente contrastado con testimonios de Cebriá y Domenech que habían sido operarios del taller durante años, así como de clientes y colaboradores, registrado en el taller de la calle San Vicente, 27, 24-11-2000

${ }^{21}$ SOLER GARCÍA,Pilar, La marquetería artística, cit., pp. 301-305 y 319-331.

${ }^{22}$ SOLER GARCÍA, Pilar, La marquetería artística, cit., p. 274.

${ }^{23}$ Los 2.300 dibujos del archivo Sagarra confirman esta vuelta al pasado.

${ }^{24}$ ORDOÑEZ, J, Marquetería, Barcelona, Parramón Ediciones, S.A., 1999

${ }^{25}$ SOLER GARCÍA, Pilar, La marquetería artística, cit., pp. 81-84.

${ }^{26}$ CORREDOR MATHEOS, José, “Artesanía de España”, Artesanías de España, Ministerio de Industria y Energía, Barcelona, Lunwerg Editores, 1999, pp. 21-24.

${ }^{27}$ PRIETO, Jesús-Ángel, http://jesusangelprieto.es/resurces/Tribuna, Butlletí d’Artesania, no 3.

Fecha de recepción: 16 de junio de 2013

Fecha de revisión: 28 de junio de 2013

Fecha de aceptación: 1 de julio de 2013 